\title{
Changes of The Microbial Community in Corn Soil Due to the Synergism Zeolite-Mineral Fertilizers
}

\author{
Roxana VIDICAN, Vlad STOIAN*, Ioan ROTAR, Florin Păcurar, Susana SFECHIȘ \\ Department of Plant Culture. University of Agricultural Sciences and Veterinary Medicine Cluj-Napoca, \\ Calea Mănăştur 3-5, 400372, Cluj-Napoca, Romania \\ * corresponding author: vlad.stoian@usamvcluj.ro
}

Bulletin UASVM series Agriculture 73(2)/2016

Print ISSN 1843-5246;

Electronic ISSN 1843-5386

DOI 10.15835/buasvmcn-agr: 12400

\begin{abstract}
Microbial communities in agricultural ecosystems are characterized by a strong dynamic and radical change due to technological inputs applied. Corn is a plant with high requirements for nutrients and an increased potential for activation of specific microbial groups. The aim of this study was to assess the unilateral and synergic effect of zeolite and mineral fertilizers on the development and transformation of microbial functional groups in the rhizosphere of corn. Physiological profile assessment of microbial communities has been carried out on the basis of substrate induced respiration, monitored over a period of 6 hours of incubation. The amount of $\mathrm{CO}_{2}$ registered in Microresp plates represents the activity of functional groups in decomposition of each type of substrate applied. Characteristic groups of microorganisms in maize rhizosphere are capable of decomposing acids: citric, L-malic, oxalic and $\alpha$-Ketoglutaric. The highest microbial activities were observed in groups of bacteria involved in processes of plant growth promotion and microbial groups with an important role in the processes of denitrification. For the application of urea a triple value of activity of this type of microflora is observed. Functional groups codominant in soils cultivated with corn are specialized in efficient degradation of organic matter and biological crust, zeolite providing the complex substrate necessary for the development of these microorganisms.
\end{abstract}

Keywords: microbial communities, fertilizer, zeolite, corn.

\section{INTRODUCTION}

Modern agricultural systems are increasingly dependent on soil-plant system management, taking into account the pressure of applied inputs and the balance of soil communities (Ehrmann și Ritz, 2014). The soil has the largest reserve of biodiversity, with high functionality and powerful processes for conversion of matter (Hinsinger et al., 2009). Microbial communities in agricultural ecosystems are characterized by a strong dynamic and radical changes due to technological inputs applied, particularly mineral nitrogen (Han et al., 2007, Ruppel et al., 2007). Rhizosphere is adapted to plant growth dynamics, with specific processes that optimize the ratio between plant requirements and the reserve of nutrients from the soil (Hodge et al., 2009, Youssef et al., 2015). The potential yield is an indicator of the performance of a plant in the context of achieving an optimum balance between microbial component from soil, nutrients reserve and development of plants (Grassinia et al., 2015, van Ittersum et al., 2013).

Corn is a plant cultivated on large areas, with yields directly proportional with the level of climatic and agronomic disturbance of soil (Cui et al., 2009, Shiferaw et al., 2011, Xiong et al., 2007). Level of fertilization and treatments applied to this culture affect drastically microbial communities (ElBestawy et al., 2013). Mechanisms of functioning and adaptation of microbial communities to the maize agronomic management ensures the stability of agro-ecosystem and provides clues on 
potential methods of maintaining soil productivity at a stable level (Blagodatskaya și Kuzyakov, 2008, Baudoin et al., 2003).

The purpose of this study was to assess the effect of unilateral and synergic application of zeolite and mineral fertilizers on the development and transformation of microbial functional groups in corn rhizosphere.

\section{MATERIALS AND METHODS}

The experiments were conducted using the method of randomized blocks, with eight variants in four replications, located on a phaeoziom argic at ARDS Turda (46³5'31.4”N $23^{\circ} 48^{\prime} 19.8^{\prime \prime}$ ) $)$. On each variant have been applied treatments with zeolite, urea, NP 20-20 or various combinations of these. The biological material was maize (Zea mays L.) Turda Star, created at ARDS Turda. Experimental variants were: V1 - control (unfertilized), V2 $200 \mathrm{~kg} \mathrm{ha}^{-1}$ urea, V3 - $200 \mathrm{~kg} \mathrm{ha}^{-1}$ zeolite, V4 - 100 $\mathrm{kg} \mathrm{ha}^{-1}$ urea $+100 \mathrm{~kg} \mathrm{ha}^{-1}$ zeolite, V5 - $140 \mathrm{~kg} \mathrm{ha}^{-1}$ urea $+60 \mathrm{~kg} \mathrm{ha}^{-1}$ zeolite, V6 - $100 \mathrm{~kg} \mathrm{ha}^{-1} \mathrm{NP} 20: 20$ + $100 \mathrm{~kg} \mathrm{ha}^{-1}$ zeolite, V7 - $175 \mathrm{~kg} \mathrm{ha}^{-1} \mathrm{NP} 20: 20+$ $25 \mathrm{~kg} \mathrm{ha}^{-1}$ zeolite, $\mathrm{V} 8-175 \mathrm{~kg} \mathrm{ha}^{-1}$ zeolite $+25 \mathrm{~kg}$ ha $^{-1}$ NP20:20.

Physiological profile assessment of microbial communities has been carried out on the basis of substrate induced respiration, monitored over a period of 6 hours of incubation (Campbell et al., 2003). The amount of $\mathrm{CO}_{2}$ recorded in Microresp plates represented the active functional groups in the decomposition of each type of substrate applied.

\section{RESULTS AND DISCUSSION}

In maize rhizosphere characteristic are the microorganisms from groups capable of decomposing citric acid, L-malic acid, oxalic acid and $\alpha$-Ketoglutaric (Tab. 1). The most spectacular increases in microbial activity are observed in the groups involved in the process of decomposition of the oxalic acid.

At the application of urea (V2) a three time increase is observed for the activity of this type of microflora (Tab 1.). A similar phenomenon is observed at differentiated application of the zeolite (V3) or zeolite as buffer for NP (V6 and V7), doubling the microbial activity compared to the control. The application of urea (V2) produces an increase of specialized groups for L-malic acid and L-cysteine, compared to unfertilized variant. Using zeolite in recipes with NP or with urea maintains the general microbial activity at a level closer to the unfertilized variant, stopping the emergence of extreme dominant groups in microbial community structure and maintaining the balance of soil.

Tab. 1. Dynamic of microbial functional groups as response to fertilization $\left(\mu \mathrm{g} \mathrm{CO}_{2}-\mathrm{C} \mathrm{g}^{-1} \mathrm{~h}^{-1}\right)$

\begin{tabular}{lcccccccc}
\hline Substrate & V1 & V2 & V3 & V4 & V5 & V6 & V7 & V8 \\
\hline Distiled water & 0.59 & 0.66 & 0.48 & 0.62 & 0.48 & 0.55 & 0.46 & 0.53 \\
\hline N-acetyl-glucosamine & 0.86 & 0.77 & 0.51 & 0.65 & 0.71 & 0.72 & 0.61 & 0.71 \\
\hline L-arginine & 0.98 & 0.21 & 0.22 & 0.18 & 0.28 & 0.29 & 0.23 & 0.20 \\
\hline Acid $\boldsymbol{\gamma}$-aminobutyric & 0.79 & 0.68 & 0.53 & 0.56 & 0.60 & 0.59 & 0.63 & 0.63 \\
\hline L-lysine & 0.87 & 0.78 & 0.51 & 0.68 & 0.73 & 0.54 & 0.66 & 0.59 \\
\hline L-alanine & 1.06 & 0.86 & 0.72 & 0.79 & 0.82 & 0.71 & 0.88 & 0.80 \\
\hline L-cisteine & 0.82 & 1.44 & 0.82 & 0.75 & 1.21 & 1.02 & 1.00 & 0.72 \\
\hline D-trehalose & 1.35 & 0.93 & 0.61 & 0.90 & 0.82 & 0.63 & 0.57 & 0.81 \\
\hline D-galactose & 1.30 & 1.11 & 0.81 & 0.93 & 0.96 & 0.99 & 1.06 & 0.77 \\
\hline L-arabinose & 1.35 & 1.29 & 0.91 & 0.76 & 1.02 & 1.07 & 0.88 & 0.84 \\
\hline D-fructose & 1.81 & 1.82 & 1.05 & 1.32 & 1.33 & 1.16 & 1.38 & 1.16 \\
\hline D-glucose & 2.00 & 1.83 & 1.28 & 1.47 & 1.74 & 1.24 & 1.41 & 1.25 \\
\hline Citric acid & 3.16 & 3.94 & 2.28 & 1.88 & 2.48 & 2.26 & 1.99 & 1.65 \\
\hline L-malic acid & 2.26 & 4.38 & 3.66 & 2.86 & 2.70 & 1.50 & 3.86 & 2.97 \\
\hline Oxalic acid & 1.52 & 5.09 & 3.62 & 2.61 & 2.03 & 3.34 & 3.61 & 2.77 \\
\hline $\boldsymbol{\alpha}$-Ketoglutaric acid & 3.84 & 3.86 & 3.37 & 2.95 & 3.41 & 2.54 & 3.08 & 2.00 \\
\hline
\end{tabular}


For the whole experiment two specific communities are highlighted based on extremely high quantities of $\mu \mathrm{g} \mathrm{CO}_{2}-\mathrm{C} \mathrm{g}^{-1} \mathrm{~h}^{-1}$ over other experimental variants (Tab. 1). For the unfertilized variant a high activity is registered of L-arginine decomposers and for urea application is visible the metabolic activity of group oxalic acid. Zeolite (V3) maintains L-cysteine group activity at levels equal to those recorded in the unfertilized variant, which indicates a reduced negative impact of this type of fertilizer. In contrast, urea (V2 and V5) and large quantities of NP (V6 and V7) increase the activity of group by at least $20 \%$.

Except basal respiration (distilled water), Lcysteine specific communities and citric acid, Lmalic acid, oxalic acid and $\alpha$-Ketoglutaric, for all other microbial communities reductions in activity were identified when compared to unfertilized variant (Tab. 1.). This indicates the existence of highly specialized groups of microorganisms for fertilization conditions. In this context a reorganization of ecological niche can be distinguished in fields cultivated with corn, specialized microorganisms in the active rhizosphere becoming dominant based on the type of fertilizer used.

Application of fertilization recipes with zeolite and mineral fertilizars produces a strong segmentation of microbial communities in maize rhizosphere. Fertilization induces the apparition of functional microbial associations needed to complete each stage of the circuit of organic matter and mineral elements (Fig. 1., 2.). Specifically, in the soil from control variant (V1) are predominant processes of decomposition of L-arginine, and for V8 - fertilized with urea oxalic acid metabolic processes are characteristic (tab. 1.). This type of specificity excludes the possibility of a dominantco-dominant type coherent associations based on the two functional groups, being removed for this reason from the NMDS graph (Fig. 1., 2.). The variance explained by the 2-axis is $94.01 \%$ (Axis 1 - 78.04\%, Axis 2 - 15.97\%), which indicates stronger effect of fertilization on the size of the functional microbial community than the other factors (temperature, precipitation), their role being the potentiation of fertilization. Unilateral application of zeolite (Tab. 2) has a significant effect on the dynamics of the microorganism in the rhizosphere (Z200, p <0.05), but enhances the quality of fertilization when is applied together with NP 20:20 in doses above $100 \mathrm{~kg} \mathrm{ha}^{-1}$ (NP100Z100, NP25Z175 - p<0.01).

Between control variant (V1) and the one fertilized with urea (V2) there is a similarity in the dynamics of citric acid, the dominant group for the two technological extreme tested (Fig. 1.). For urea (V3) is difficult to establish a single co-dominant group due to the high amount of nitrogen applied, but a succession of microbial communities installed on the same feeding niche is highlighted. With the transformation process of the oxalic acid in the variant fertilized with urea (V2), L-malic acid metabolism is stimulated with the same intensity. The inclusion of zeolite as buffer for mineral fertilization moderates these extreme reactions, uncontrolled proliferation of a microbial functional group and emerging imbalances in the soil being avoided.

Low doses of zeolite (V7) or unilateral application of this fertilizer balances the microbiologi-

Tab. 2. The importance of fertilization in the dynamics of microbial communities

\begin{tabular}{lcccc}
\hline & NMDS1 & NMDS2 & r2 & Pr(>r) \\
\hline F0 & -0.487 & -0.873 & 0.485 & $0.001^{* * *}$ \\
\hline U200 & -0.702 & 0.712 & 0.471 & $0.001^{* * *}$ \\
\hline Z200 & 0.160 & 0.987 & 0.234 & $0.027^{*}$ \\
\hline U100Z100 & 0.992 & -0.129 & 0.035 & 0.609 \\
\hline U140Z60 & -0.414 & -0.910 & 0.015 & 0.826 \\
\hline NP100Z100 & 0.280 & -0.960 & 0.395 & $0.002^{* *}$ \\
\hline NP175Z25 & 0.130 & 0.991 & 0.098 & 0.196 \\
\hline & 0.980 & 0.198 & 0.233 & $0.009^{* *}$ \\
\hline
\end{tabular}




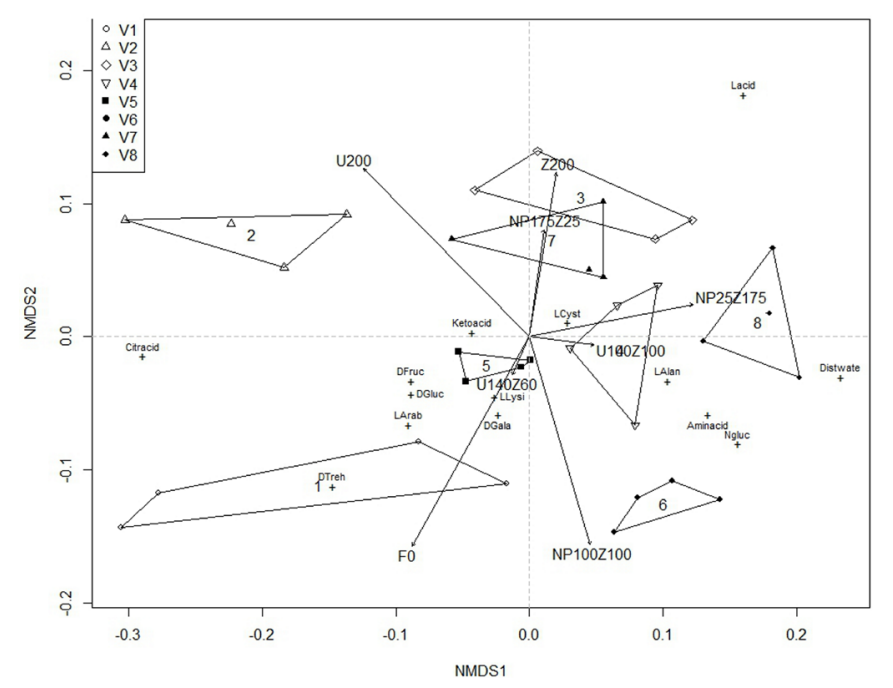

Fig. 1. Functional microbial communities determined fertilization

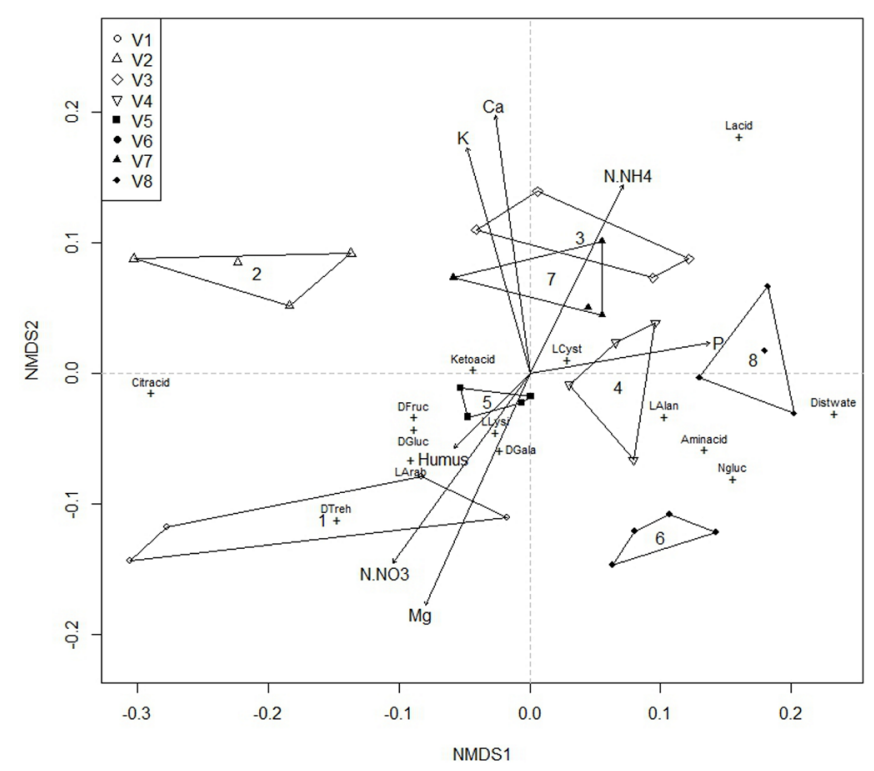

Fig. 2. Interaction fertilizer - microbial community - minerals

cal processes, stabilizing the succession of groups of microorganisms and stopping the emergence of a completely dominant group in the rhizosphere (Fig. 1). However, in time, zeolite can stimulate the emergence of strong differences to natural communities (specific to V1) and for this reason is much better utilized associated with fertilization.

$\mathrm{N}$-acetyl-glucosamine and $\gamma$-aminobutyric acid decomposition is reduced after applying zeolite in combination with mineral fertilization (Fig. $1,2)$. The sensitivity of these groups of microorganisms to zeolite reduces the risk of proliferation and phenomena is beneficial to avoid the export of mineral elements in the environment followed by immobilization or loss of nutrients due to a lack of microbial codominant groups. The most stable fertilization variant has a recipe composed of U140Z60 (V5), microbial community having a balanced structure. In this case there is no dominant functional group in the rhizosphere.

Zeolite application (V3) stimulates significant accumulation of ammonia, calcium and potassium in soil (Fig. 2., Tab. 3). In unfertilized soils $\mathrm{N}^{-N_{3}}$ and magnesium is accumulated along with the increase of the percentage of humus, effect achieved as unequal application of the zeolite and urea 
Tab. 3. Sensitivity of mineral elements translocation in soil

\begin{tabular}{lcccc}
\hline & NMDS1 & NMDS2 & r2 & Pr(>r) \\
\hline $\mathbf{P}$ & 0.986 & 0.166 & 0.208 & $0.045^{*}$ \\
\hline $\mathbf{K}$ & -0.268 & 0.964 & 0.344 & $0.002^{* *}$ \\
\hline $\mathbf{H u m u s}$ & -0.711 & -0.703 & 0.071 & 0.344 \\
\hline $\mathbf{C a}$ & -0.131 & 0.991 & 0.424 & $0.001^{* * *}$ \\
\hline $\mathbf{M g}$ & -0.410 & -0.912 & 0.405 & $0.002^{* *}$ \\
\hline $\mathbf{N . N O 3}$ & -0.585 & -0.811 & 0.343 & $0.004^{* *}$ \\
\hline $\mathbf{N . N H 4}$ & 0.443 & 0.896 & 0.278 & $0.010^{* *}$ \\
\hline & Signif. codes: $0^{\text {(***) }} 0.001^{\text {(**) }} 0.01^{\text {** }} 0.05^{\prime \prime} 0.1^{\prime \prime} 1$ &
\end{tabular}

(V5). Phosphorus is immobilized much faster in soils fertilized with at least $100 \mathrm{~kg} \mathrm{ha}^{-1}$ zeolite (V4 and V8) regardless of the type of mineral fertilizer.

\section{CONCLUSION}

Applied fertilizers determine relevant changes in the microbial community profile. Maize rhizosphere is dominated by groups that metabolize L-malic acid and oxalic acid, due to the influence of zeolite. Co-dominant functional groups are specialized in effective degradation of $\alpha$-Ketoglutaric acid and citric acid.

\section{REFERENCES}

1. Baudoin E, Benizri E, Guckert A (2003). Impact of artificial root exudates on the bacterial community structure in bulk soil and maize rhizosphere. Soil Biol Biochem 35:1183-1192

2. Blagodatskaya E, Kuzyakov Y (2008). Mechanisms of real and apparent priming effects and their dependence on soil microbial biomass and community structure: critical review. Biology and Fertility of Soils, 45(2):115-131.

3. Cui Z, Zhang F, Mi G, Chen F, Li F, Chen X, Shi L (2009). Interaction between genotypic difference and nitrogen management strategy in determining nitrogen use efficiency of summer maize. Plant and soil, 317(1-2):267276.

4. Ehrmann J, Ritz K (2014). Plant: soil interactions in temperate multi-cropping production systems. Plant and Soil, 376(1-2):1-29.

5. El-Bestawy E, Sabir J, Mansy AH, Zabermawi N (2013). Isolation, identification and acclimatization of Atrazineresistant soil bacteria. Annals of Agricultural Sciences, 58(2):119-130.

6. Gil SV, Meriles J, Conforto C, Figoni G, Basanta M, Lovera E, March GJ (2009). Field assessment of soil biological and chemical quality in response to crop management practices. World Journal of Microbiology and Biotechnology, 25(3):439-448.
7. Grassini P, van Bussel LG, Van Wart J, Wolf J, Claessens L, Yang H, Cassman KG (2015). How good is good enough? Data requirements for reliable crop yield simulations and yield-gap analysis. Field Crops Research, 177:49-63.

8. Han G, Zhou G, Xu Z, Yang Y, Liu J, Shi K (2007). Soil temperature and biotic factors drive the seasonal variation of soil respiration in a maize (Zea mays L.) agricultural ecosystem. Plant and Soil, 291(1-2):15-26.

9. Hinsinger P, Bengough AG, Vetterlein D, Young IM (2009). Rhizosphere: biophysics, biogeochemistry and ecological relevance. Plant and soil, 321(1-2): 117-152.

10. Hodge A, Berta G, Doussan C, Merchan F, Crespi M (2009). Plant root growth, architecture and function. Plant and soil, 321(1-2): 153-187.

11. Philippot L, Kuffner M, Chèneby D, Depret G, Laguerre G, Martin-Laurent F (2006). Genetic structure and activity of the nitrate-reducers community in the rhizosphere of different cultivars of maize. Plant and soil, 287(1-2): 177186.

12. Ruppel S, Torsvik V, Daae FL, Øvreås L, Rühlmann J (2007). Nitrogen availability decreases prokaryotic diversity in sandy soils. Biology and Fertility of Soils, 43(4): 449-459.

13. Shiferaw B, Prasanna BM, Hellin J, Bänziger M (2011). Crops that feed the world 6. Past successes and future challenges to the role played by maize in global food security. Food Security, 3(3): 307-327.

14. van Ittersum MK, Cassman KG, Grassini P, Wolf J, Tittonell P, Hochman Z (2013). Yield gap analysis with local to global relevance-a review. Field Crops Research, 143: 4-17.

15. Xiong W, Matthews R, Holman I, Lin E, Xu Y (2007). Modelling China's potential maize production at regional scale under climate change. Climatic change, 85(3-4):433451.

16. Youssef HH, Hamza MA, Fayez M, Mourad EF, Saleh MY, Sarhan MS, Ruppel S (2016). Plant-based culture media: Efficiently support culturing rhizobacteria and correctly mirror their in-situ diversity. Journal of advanced research, 7(2):305-316. 